\title{
Transformation-Induced Plasticity in Super Duplex Stainless Steel F55-UNS S32760
}

\author{
Andrea Francesco Ciuffini ${ }^{1, *}{ }^{\mathbb{D}}$, Silvia Barella $\left.{ }^{1} \mathbb{(}\right)$, Cosmo Di Cecca ${ }^{1}$, Andrea Di Schino ${ }^{2} \mathbb{D}$, \\ Andrea Gruttadauria ${ }^{1}$, Giuseppe Napoli ${ }^{2}$ D and Carlo Mapelli ${ }^{1}$ \\ 1 Dipartimento di Meccanica, Politecnico di Milano, via La Masa 34, 20156 Milano, Italy; \\ silvia.barella@polimi.it (S.B.); cosmo.dicecca@polimi.it (C.D.C.); andrea.gruttadauria@polimi.it (A.G.); \\ carlo.mapelli@polimi.it (C.M.) \\ 2 Dipartimento di Ingegneria, Università degli Studi di Perugia, via G. Duranti, 06125 Perugia, Italy; \\ andrea.dischino@unipg.it (A.D.S.); giuseppe.napoli@studenti.unipg.it (G.N.) \\ * Correspondence: andreafrancesco.ciuffini@polimi.it; Tel.: +39-340-125-3162
}

Received: 17 January 2019; Accepted: 3 February 2019; Published: 6 February 2019

\begin{abstract}
Due to their unique combination of properties, Super Duplex Stainless Steels (SDSSs) are materials of choice in many industries. Their applications and markets are growing continuously, and without any doubt, there is a great potential for further volume increase. In recent years, intensive research has been performed on lean SDSSs improving mechanical properties exploiting the lack of nickel to generate metastable $\gamma$-austenite, resulting in transformation-induced plasticity (TRIP) effect. In the present work, a commercial F55-UNS S32760 SDSS have been studied coupling its microstructural features, especially secondary austenitic precipitates, and tensile properties, after different thermal treatments. First, the investigated specimens have been undergone to a thermal treatment solution, and then, to an annealing treatment with different holding times, in order to simulate the common hot-forming industrial practice. The results of microstructural investigations and mechanical testing highlight the occurrence of TRIP processes. This feature has been related to the Magee effect, concerning the secondary austenitic precipitates nucleated via martensitic-shear transformation.
\end{abstract}

Keywords: steel; austenite; mechanical characterization; martensitic transformations; phase transformation

\section{Introduction}

Duplex stainless steels (DSSs), and consequently, Super Duplex stainless steels (SDSSs) consist of austenite and ferrite phases. The resultant microstructure exhibits good combinations of strength, ductility, and corrosion resistance, since it takes advantages of the single-phase counterparts [1], with the main difference from more common austenitic stainless steels [2,3]. The steels not only inherit the mechanical properties of the completely ferritic or completely austenitic alloys, but they also exceed them. A factor of economic importance is the low content of expensive nickel, usually $4-7 \%$ compared with $10 \%$ or more in austenitic grades, as a result of which the life cycle cost of the DSSs is the lowest in many applications [4-7]. In DSSs, the two structure components b.c.c $\alpha$-ferrite and f.c.c. $\gamma$-austenite lies as crystals of the same size statistically distributed next to each other [8]. However, adjustment of the two-phase microstructure of duplex stainless steels is complicated because a balanced phase ratio does not only depend on alloy components [9]. Indeed, the decomposition of ferrite to austenite can occur over a wide temperature range. This phenomenon can be understood on the basis that the duplex structure is quenched from a higher temperature, at which the equilibrium fraction of $\alpha$-ferrite is higher. There appear to be three mechanisms by which austenite can precipitate within 
$\alpha$-ferrite grains: By the eutectoid reaction, as Widmannstätten precipitates, and via a martensitic shear process [9-11]. Martensitic transformation in solids provides an unusual mechanical behavior ranging from the superelastic behavior typical of shape-memory alloys to non-thermoelastic behavior where the transformation induced plasticity (TRIP) phenomenon allows the development of steels with a good compromise between ductility and toughness [12-15]. This typical property of TRIP-aided steels results from the strong couplings between plasticity by dislocation motion and martensitic phase transformation through the internal stresses generated by both inelastic processes. The TRIP mechanism is based on deformation-stimulated displacive transformation of a metastable former phase. In such materials, the overall behavior depends deeply on the so-called chemical energy, which leads the martensitic shear transformation. The motivation for that is twofold. First, the former phase should be sufficiently unstable such that a transformation-induced plasticity effect is initiated upon loading. Second, the former phase should be sufficiently stable that the TRIP effect occurs over a wide strain regime, specifically at high strains, where strain-hardening reserves are usually more desirable than at low strains. In order to obtain this phenomenon in DSS steels, different studies have been recently performed; designing new alloys compositions [16-18]. The aim of this work is to achieve the occurrence of the TRIP effect in SDSSs commercial alloys, exploiting the martensitic shear transformation of the $\gamma$-austenite within $\alpha$-ferritic grains, just by tuning the proper thermal treatment.

\section{Materials and Methods}

This study has been performed on a commercial F55-UNS S32760 super duplex stainless steel, which had a chemical composition, as designed by standards and measured via optical emission spectroscopy (OES), is reported in Table 1. Samples have been drawn from a bulk ingot and thermally treated. First, a solution thermal treatment (STT) at $1573 \mathrm{~K}\left(130{ }^{\circ} \mathrm{C}\right)$ for $145 \mathrm{~s} / \mathrm{mm}$ has been executed, in order to erase the previous thermal and stress history of the specimens and to provide the super-saturation of the $\alpha$-ferritic matrix with $\gamma$-formers elements, such as $\mathrm{Ni}, \mathrm{Mn}, \mathrm{Cu}$, and N. Then, an annealing thermal treatment (ATT) has been performed at $1353 \mathrm{~K}\left(1080{ }^{\circ} \mathrm{C}\right)$ for different holding times: 36, 72, 215, 355, 710, and $1135 \mathrm{~s} / \mathrm{mm}$ (Figure 1). The purpose of this heat treatment is the supply of the energy needed to trigger the $\gamma$-austenite precipitation within the $\alpha$-matrix. This temperature range grants to avoid precipitation of embrittling phases within $\alpha$-ferritic grains, such as $\sigma(\mathrm{Fe}-\mathrm{Cr}-\mathrm{Mo}), \chi\left(\mathrm{Fe}_{36} \mathrm{Cr}_{12} \mathrm{Mo}_{10}\right)$, and nitrides $\left(\mathrm{CrN}\right.$ and $\left.\mathrm{Cr}_{2} \mathrm{~N}\right)$. Both thermal treatments have been followed by water quench [19]. Afterwards, specimens have been machined into Round Tension Test Specimen shapes and tensile tests have been performed; both these operations have been executed, following the ASTM E8/E8M standard. The specimens have been treated for the microstructural examination using Beraha's tint etching $\left(5 \mathrm{~mL} \mathrm{H}_{2} \mathrm{O}, 1 \mathrm{~mL} \mathrm{HCl}, 0.06 \mathrm{~g} \mathrm{~K}_{2} \mathrm{~S}_{2} \mathrm{O}_{5}, 0.06 \mathrm{~g}\right.$ $\mathrm{NH}_{4} \mathrm{FHF}$ ). Subsequently, the samples have been analyzed via stereoscopy, optical microscopy, and electron microscopy. The volume fraction of $\gamma$-austenite within the material has been calculated through automatic image analysis of 10 micrographs measuring $1 \mathrm{~mm}^{2}$ randomly taken on the samples, following ASTM E1245 standard. Electron microscopy has been used in order to obtain morphological information via Secondary Electron (SEM/SE) imaging, chemical composition data through Energy-Dispersive X-ray Spectroscopy (SEM/EDS), and crystallographic data by Electron Backscatter Diffraction (SEM/EBSD) analysis. The beam spot has $1 \mu \mathrm{m}$ radius. The chemical composition data have been obtained, averaging five measures. The Electron Backscatter Diffraction (SEM/EBSD) analysis has been calculated through the software INCA provided by Oxford Instruments (INCA Oxford Instrument, Oxford, UK). The crystallographic data have been used to highlight the influence of grain boundary distribution on the onset of secondary recrystallization. The presence of special Coincidence Site Lattice (CSL) boundaries between primary and secondary grains the development of recrystallization. 
Table 1. UNS S32760 super duplex stainless steel chemical composition (expressed in wt.\%), as designed by standards and measured via optical emission spectroscopy (OES).

\begin{tabular}{ccccccccccc}
\hline \multirow{2}{*}{ F55-UNS S32766 } & $\mathbf{1 0}$ & \multicolumn{10}{c}{ Wt. \% } \\
\cline { 2 - 12 } & $\mathbf{C}$ & $\mathbf{M n}$ & $\mathbf{S i}$ & $\mathbf{C r}$ & $\mathbf{N i}$ & $\mathbf{M o}$ & $\mathbf{N}$ & $\mathbf{C u}$ & $\mathbf{W}$ & $\mathbf{F e}$ \\
\hline Designation & $<0.03$ & $<1.00$ & $<1.00$ & $24.0-26.0$ & $6.0-8.0$ & $3.0-4.0$ & $0.2-0.3$ & $0.5-1.0$ & $0.5-1.0$ & Bal. \\
OES measure & 0.027 & 0.63 & 0.51 & 24.37 & 6.69 & 5.45 & 0.22 & 0.72 & 0.85 & Bal. \\
\hline
\end{tabular}

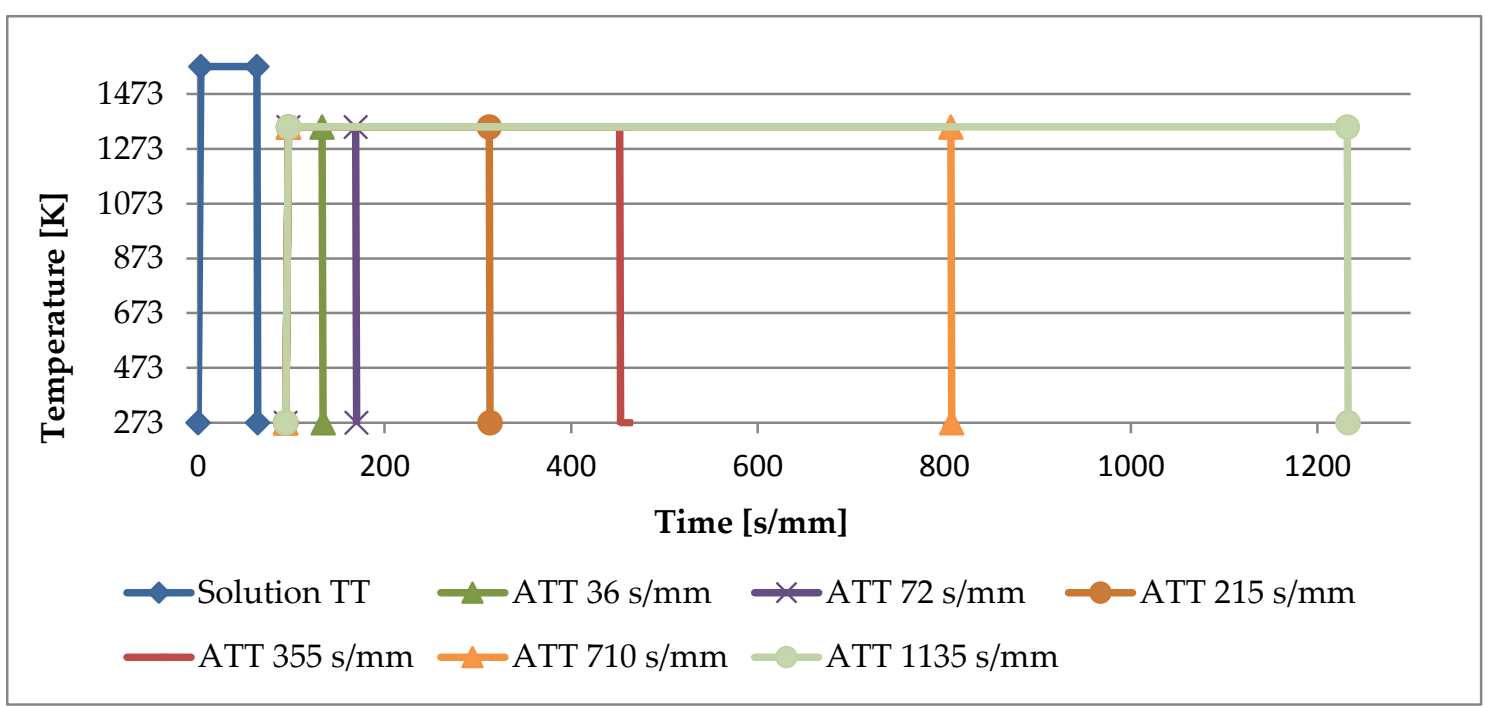

Figure 1. Diagram representing the thermal treatments parameters.

\section{Results}

Optical microscopy analysis of the F55-UNS S32760 super duplex stainless steel samples have been performed after the execution of the heat treatments. The resulting microstructures of the different specimens have been reported in Figure 2. Micrographs display different phase fraction ratios in accordance with the different holding time of the heat treatments (Table 2).

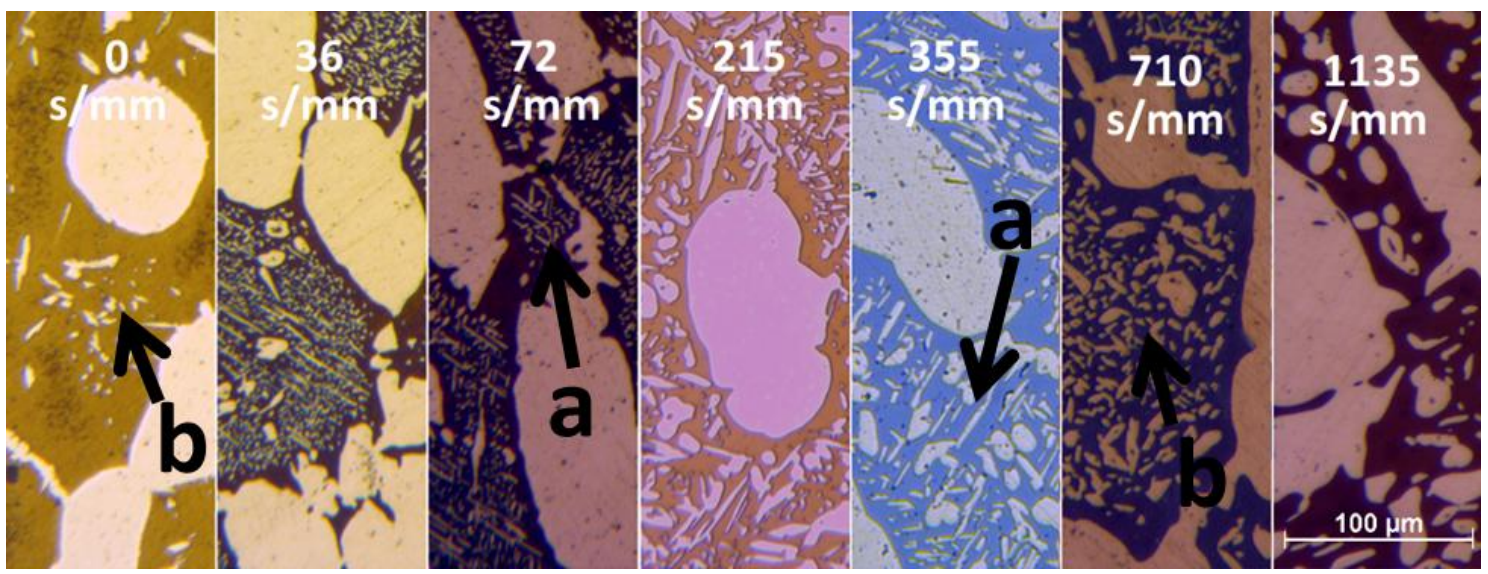

Figure 2. $\quad \gamma$-Austenite content variation during isothermal annealing treatment assessed via metallographic method and sample micrographs of each stage of UNS S32760 evolution. The precipitation of $\gamma$-austenitic nuclei, as Widmannstätten precipitates (a) and via a martensitic shear process (b) within the $\alpha$-ferritic matrix, is displayed in Reference [7]. 
Table 2. $\gamma$ volume fraction of the $\gamma$-austenitic grains during the isothermal annealing at $1353 \mathrm{~K}$ $\left(1080^{\circ} \mathrm{C}\right)$.

\begin{tabular}{cccccccc}
\hline Annealing Soaking Times [s/mm] & 0 & 36 & 72 & 215 & 355 & 710 & 1135 \\
\hline$\gamma$ Volume Fraction & 0.36 & 0.49 & 0.54 & 0.40 & 0.54 & 0.41 & 0.41 \\
Error & 0.03 & 0.02 & 0.05 & 0.01 & 0.01 & 0.04 & 0.02 \\
\hline
\end{tabular}

The scanning electron microscope through Energy-Dispersive X-ray Spectroscopy (SEM/EDS) can investigate the chemical features of the phases belonging to the material. In particular, the way in which alloying elements distributes inside ferrite rather than inside austenite and can be appreciated [20,21]. The most significant results of the chemical composition analysis are hence briefly reported in the following (Table 3), considering that the concentration of each element is expressed as a percentage by weight.

Table 3. SEM/EDX chemical analysis of the $\alpha$-ferritic matrix. The profile of Ni concentration, with the ongoing of the annealing thermal treatment, testifies the supersaturation of $\alpha$-ferritic matrix with $\gamma$-formers elements, such as $\mathrm{Ni}, \mathrm{Mn}$, and $\mathrm{Cu}$.

\begin{tabular}{cccccccccc}
\hline \multirow{2}{*}{ Specimen } & \multirow{2}{*}{ Area } & \multicolumn{7}{c}{ Wt.\% } \\
\cline { 3 - 9 } & & Fe & Cr & Ni & Mo & W & Cu & Mn & Si \\
\hline STT $1300{ }^{\circ} \mathrm{C}$ & $\alpha$-ferrite & $60.85 \pm 0.31$ & $24.92 \pm 0.46$ & $6.23 \pm 0.28$ & $5.11 \pm 0.33$ & $0.80 \pm 0.11$ & $0.90 \pm 0.07$ & $0.67 \pm 0.32$ & $0.52 \pm 0.19$ \\
ATT $36 \mathrm{~s} / \mathrm{mm}$ & $\alpha$-ferrite & $61.68 \pm 0.42$ & $23.45 \pm 0.34$ & $4.98 \pm 0.32$ & $7.02 \pm 0.28$ & $0.80 \pm 0.12$ & $0.88 \pm 0.9$ & $0.61 \pm 0.19$ & $0.58 \pm 0.17$ \\
ATT $1135 \mathrm{~s} / \mathrm{mm}$ & $\alpha$-ferrite & $63.37 \pm 0.35$ & $23.24 \pm 0.41$ & $4.37 \pm 0.27$ & $6.49 \pm 0.22$ & $1.08 \pm 0.8$ & $0.54 \pm 0.15$ & $0.51 \pm 0.14$ & $0.40 \pm 0.10$ \\
\hline
\end{tabular}

The tensile tests results, provided in Table 4, show the interesting mechanical features typical of SDSSs, which not only match the mechanical properties of the completely ferritic or completely austenitic alloys, but also overcoming them. A wide strain regime, specifically at high strains $(\varepsilon>0.15)$, where strain hardening reserves are usually more desirable than at low strains, is displayed by all the annealing treated samples, resulting in good plastic behavior [22]. These specimens all result in a good compromise between ductility, toughness, and elastic regime properties. Thus, the best combination of both strength and plasticity is displayed by the samples annealed treated for $36 \mathrm{~s} / \mathrm{mm}$.

Table 4. UNS S32760 tensile test results: the specimen annealed thermal treated at $1353 \mathrm{~K}\left(1080^{\circ} \mathrm{C}\right)$ for $36 \mathrm{~s} / \mathrm{mm}$ holding time show the best combination of elastic and plastic properties.

\begin{tabular}{ccccccc}
\hline $\begin{array}{c}\text { Annealing } \\
\text { Time [s/mm] }\end{array}$ & $\boldsymbol{\gamma} \%$ & $\boldsymbol{\sigma}_{\mathbf{y}}[\mathbf{M P a}]$ & $\boldsymbol{\sigma}_{\mathbf{M a x}}[\mathbf{M P a}]$ & $\boldsymbol{\varepsilon}_{\mathbf{R}}$ & $\mathbf{E}[\mathrm{GPa}]$ & $\begin{array}{c}\text { Adsorbed } \\
\text { Energy [J/mm }^{3} \text { ] }\end{array}$ \\
\hline 0 & 35.7 & 653 & 828 & 0.225 & 255 & 176 \\
36 & 49.3 & 603 & 849 & 0.334 & 211 & 260 \\
72 & 54.0 & 572 & 839 & 0.302 & 211 & 230 \\
215 & 39.7 & 533 & 826 & 0.315 & 112 & 237 \\
355 & 53.8 & 554 & 827 & 0.282 & 181 & 212 \\
710 & 41.4 & 560 & 803 & 0.293 & 190 & 215 \\
1135 & 41.3 & 547 & 824 & 0.300 & 245 & 226 \\
\hline
\end{tabular}

Further, a post-mortem morphological analysis of the tensile specimens has been performed. A visual inspection and stereoscopic analysis, as reported in Figure 3a, can highlight that all the samples show a cup-cone fracture and surface orange peel features. These results are in a good agreement with the highly ductile behavior observed during the tensile tests. Fully ductile fractures, showing very high dimples densities, are observed in all the specimens via SEM/SE morphological imaging, as reported in Figure 3b. Again, these results confirm the tensile tests data. Via optical micrographic analysis of the fracture surface sections, different features can be observed. As shown in Figure 3c, the crack path should be highlighted; the growing cracks appear to preferentially contour the $\gamma$-austenitic grains, or eventually, to cross them in a straightforward way. As a consequence, it can 
be pointed out that a lower cohesive strength of the $\alpha / \gamma$ interfaces, with respect to the $\gamma / \gamma$ internal interfaces or twinning interfaces within $\gamma$ grains, and even more, with respect to the continuous lattice of the grains interior. Further, as reported in Figure 3d, along the fracture surface, a greater density of small $\gamma$-austenitic nuclei within the $\alpha$-matrix with respect to the un-deformed areas of the specimens has been observed.

Finally, dislocations slip bands, generated by the great-imposed strain, became visible even through optical microscopy, underlining the local direction of the stress field and the response of the single grains. As expected, $\gamma$-austenitic grains show a much higher density of dislocations slip bands, testifying to the intense strain experienced preferentially by $\gamma$-grains, as displayed in Figure 3e [23].
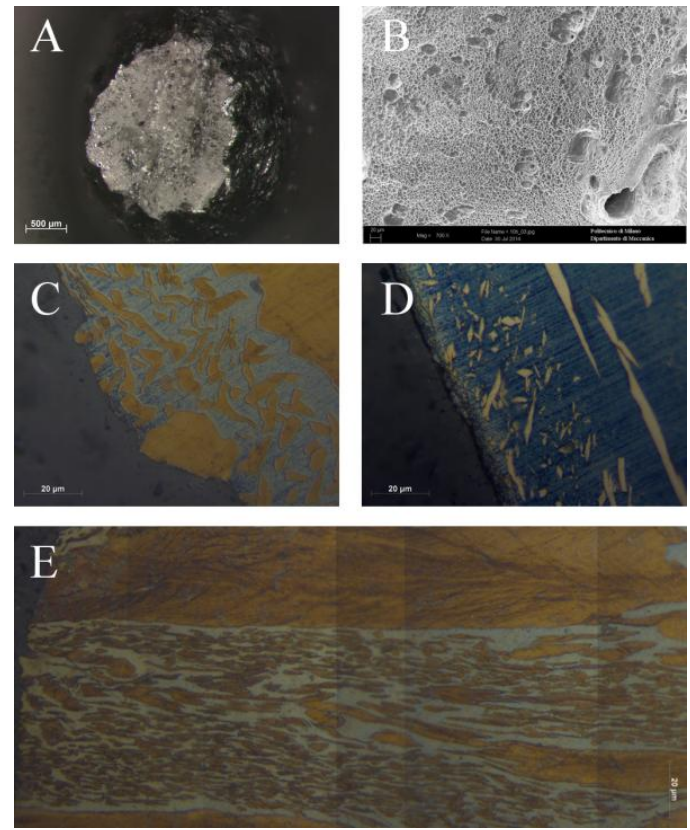

Figure 3. Post-mortem analysis of the tensile samples: stereoscopy morphological imaging of the sample annealing treated for $355 \mathrm{~s} / \mathrm{mm}$ (A), SEM/SE morphological imaging of the specimen annealing treated for $710 \mathrm{~s} / \mathrm{mm}(\mathbf{B})$, optical micrography of the fracture surface section of the specimen annealing treated for $1135 \mathrm{~s} / \mathrm{mm}(\mathrm{C})$, optical micrography of the fracture surface section of the sample annealing treated just solution heat treated (D), and optical micrography of the fracture surface section of the specimen annealing treated for $36 \mathrm{~s} / \mathrm{mm}(\mathbf{E})$.

Finally, the occurrence of a transformation induced phenomenon can be definitively confirmed by the assessment of the newly nucleation of the martensitic shear $\gamma$-nuclei along dislocations slip bands aligned to the dislocations structure via SEM/EBSD analysis, occurring after high strains have been experienced by the material. Taking into account the infinity of possible orientations of two grains relative to each other, some special orientations may be found. When some lattice points of the two lattices exactly coincide, a kind of superstructure, called coincidence site lattice (CSL), develop. The coincidence site lattice (CSL) model can be used as a standard for the characterization of grain boundary structure for poly-crystals. The frequency of occurrence of a particular type of CSL grain boundary is inherently associated with the newly recrystallized grains form a preferred crystallographic orientation relative to the deformed grains. The CSL frequency occurrence has been determined for the martensitic shear $\gamma$-nuclei aligned to the dislocations structure shown in detail in Figure 7 and for other martensitic shear $\gamma$-precipitates present within un-deformed $\alpha$-ferritic grains, as reported in Figure 4. In detail, CSL boundaries $\Sigma 13$ for f.c.c. lattices are associated to fast moving boundaries, testifying to the occurrence of nucleation and growth phenomena [24-26]. 

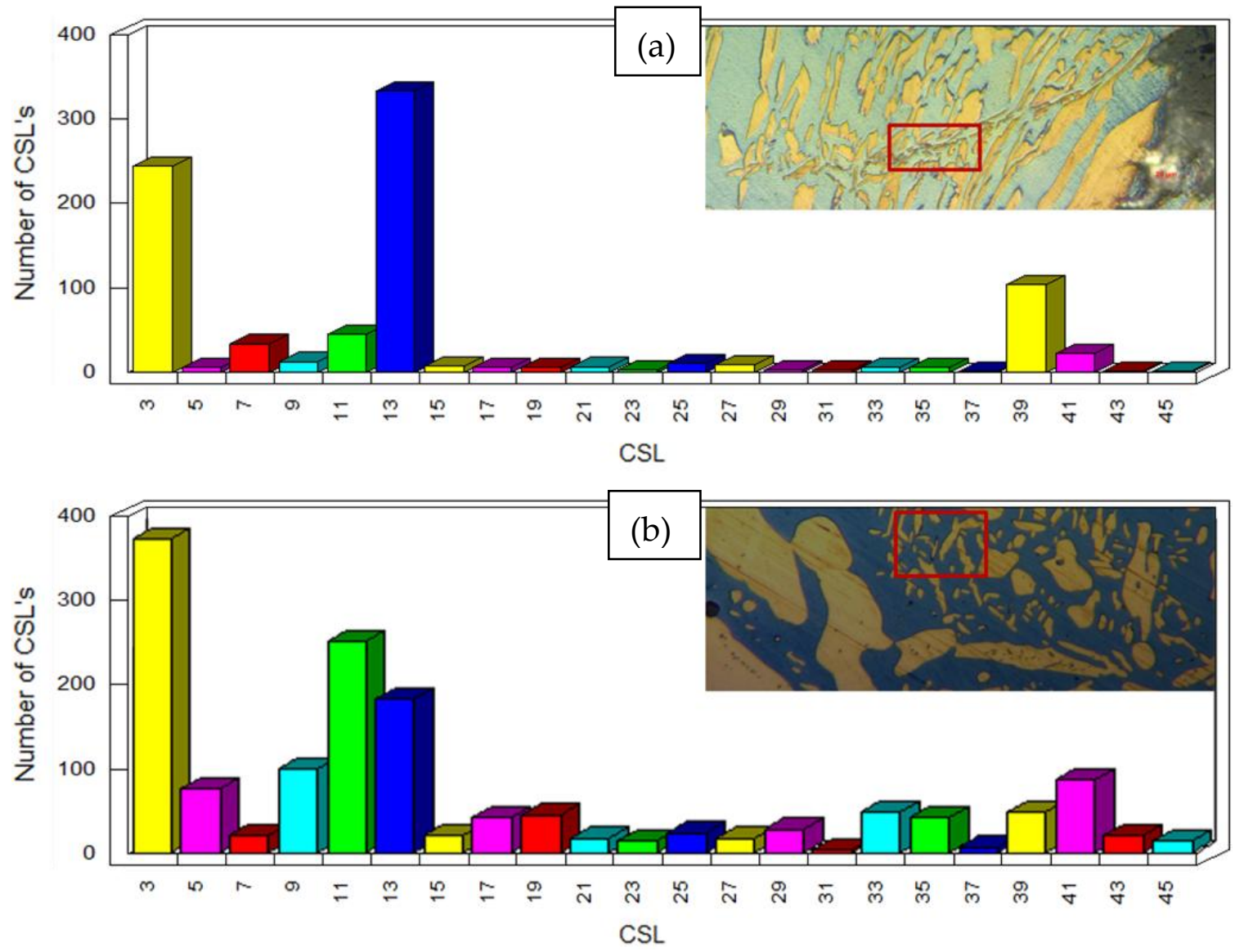

Figure 4. Comparison between CSL frequency occurrences of the martensitic shear $\gamma$-nuclei aligned to the dislocations structure shown in Figure 6 (a) and for other martensitic shear $\gamma$-precipitates present within un-deformed $\alpha$-ferritic grains (b). The increase in CSL boundaries $\Sigma 13$, testifying to the occurrence of nucleation and growth phenomena, and thus, of transformation induced plasticity phenomena.

\section{Discussion}

From the results of the experimental campaign, it is possible to express different considerations pointing out the occurrence of a TRIP phenomenon during the deformation of a commercial F55-UNS S32760 SDSS. In detail, micrographs, collected through optical microscopy, display different microstructures in accordance to the different holding time of the heat treatments. After the solution thermal treatments, the samples show a strong misproportion in the phases volume fraction from the ideal 1:1. The ferritic phase has a strong increase, as reported in Table 2. Further, specimens are featured by $\gamma$-austenite grains, embedded in $\alpha$-ferrite matrix, supersaturated in $\gamma$-stabilizers elements, such as $\mathrm{Ni}, \mathrm{Mn}, \mathrm{Cu}$, and $\mathrm{N}$ (Table 3). A consequence of this super-saturation is the segregation of $\gamma$-stabilizers elements, resulting in $\gamma$-austenite thick plates located at $\alpha$-grain boundaries, which interconnect the $\gamma$-austenitic grains. Another result of the super-saturation is the presence of the early stages of the $\alpha$-intragranular $\gamma$-nuclei nucleated during the cooling path; both Widmanstätten grain boundaries saw-teeth structures and Martensitic Shear products nuclei can be detected (Figure 2) [8,27]. The annealing thermal treatment produces the precipitation of $\gamma$-austenitic nuclei as Widmannstätten precipitates and via a martensitic-shear process within the $\alpha$-ferritic matrix. Further, the $\gamma$-precipitates display different sizes, which result in becoming larger with the ongoing of the annealing thermal treatment, according to the well-known Ostwald ripening model $[7,10,28,29]$. The super-saturation of the $\alpha$-matrix with $\gamma$-formers elements has been proven via SEM/EDX chemical analysis (Table 3). The data show a very high nickel concentration within the $\alpha$-matrix after the solution thermal treatment. 
Further, after the $36 \mathrm{~s} / \mathrm{mm}$ long annealing heat treatment, the nickel concentration still results much higher with respect to the $1135 \mathrm{~s} / \mathrm{mm}$ long annealing heat treatment, which can be considered as an equilibrium value due to such long holding time at a constant annealing temperature. Such a strong difference in nickel concentration testifies to the residual presence of the chemical free-energy, which leads the martensitic shear transformation from $\alpha$-ferrite to $\gamma$-austenite [30]. This condition would allow further nucleation and growth phenomena of the $\gamma$-austenitic precipitates, generated by martensitic shear transformation. Since this kind of phase transformation can also be activated at room temperature by the presence of a stress or strain field within the former lattice. Thus, the $\alpha$-ferritic matrix could act as a former phase, via a deformation-stimulated displacive martensitic shear transformation, of a transformation induced plasticity (TRIP) phenomenon [18,21,31].

Focusing the attention on the tensile tests results reported in Table 4, the best combination of both strength and plasticity is displayed by the samples annealed treated for $36 \mathrm{~s} / \mathrm{mm}$. In these specimens, as shown before (Figure 2), the precipitation phenomena of the $\gamma$ nuclei within the $\alpha$-ferritic matrix via martensitic shear transformation have already occurred. However, since the Oswald ripening processes have just started during the annealing thermal treatment, the $\gamma$-former elements are still enriching the $\alpha$-matrix and they are still present within the $\alpha$-matrix at high concentrations (Table 3). This condition allows the material to undergo further phase transformations, suggesting, coupled with the mechanical response in the plastic field of the other annealed treated samples, the occurrence of a transformation induced plasticity effect. Further, combining the mechanical data with the main microstructural feature, the austenitic phase volume fraction allows for the observation that there is not a good correspondence between them. Moreover, no specific trends or correspondences can be highlighted, as shown in Figure 5. Indeed, the different microstructural phase ratio deeply influences the mechanical properties, since the two constituent phases own different micromechanical features, but their influence acts in a complex way [32].

Different hardening mechanisms are known to act in DSSs. In keeping with the additivity law, ferrite hardens the austenitic matrix. Additionally, DSSs usually have a fine grain microstructure, which additionally contributed to the hardening effect, according to the Hall-Petch relationship. In the present case, the $\gamma$-precipitation within the $\alpha$-matrix in both its forms leads to a grain refinement. Moreover, SDSSs additionally harden due to the increased percentage of alloying elements, such as chromium and molybdenum in solid solution $[33,34]$.

While these hardening phenomena have been taken into account, again, a good correspondence with the tensile tests results cannot be pointed out. Thus, the high mechanical response during the tensile tests has to be investigated under a different point of view, in order to explain the obtained results.

Regarding the data of the morphological observation of the specimens undergone to the tensile tests, it is possible to observe other aspects featuring the behavior of this material. As shown in Figure $3 c$, the crack path preferentially contours the $\gamma$-austenitic grains. As a consequence, a lower bonding strength of the $\alpha / \gamma$ interfaces can be seen, with respect to other sites $(\gamma / \gamma$ internal interfaces, twinning, and the lattice of the grains interior). Since the extremely ductile behavior displayed by the studied steels, this lower resistance of $\alpha / \gamma$ interfaces has to be linked to two different mechanisms. The presence of tiny particles, usually carbides or nitrides, at the grain boundaries generates the dimples that will cause the final rupture; however, no particles have been detected, and then, this mechanism would not be the main one involved (Figure $3 \mathrm{~b}$ ). The second possible process is intrinsically related to the duplex structure nature: Dislocations in $\gamma$-austenite pile up against the $\alpha / \gamma$ phase boundaries and create a local stress concentration, which generates both dislocations in $\alpha$-ferrite or steps at the surface grains near the $\alpha / \gamma$ phase boundaries, which coarsen into the dimples [35]. Moreover, as reported in Figure $4 d$, the density and the dimensions of the small $\gamma$-austenitic nuclei within the $\alpha$-matrix drastically increase along the fracture surface with respect to the un-deformed areas of the tensile specimens. These areas are subjected to very intense strains. A much higher density of dislocations slip bands have been generated, especially within $\gamma$-grains, testifying the intense strain 
experienced preferentially by $\gamma$-grains, as displayed in Figure 4e, underlining the local direction of the stress field and the response of the single grains. Coupling these last two considerations, the definition of the Magee effect can be obtained, which is one of the two possible causes of a transformation induced plasticity phenomenon. This event consists in a stress-assisted nucleation or growth of crystallographic variants, which are favorably aligned with the orientation of the applied stress, and it may be predominant in particular for the diffusion-less martensitic shear phase transformations in steels $[32,36]$.
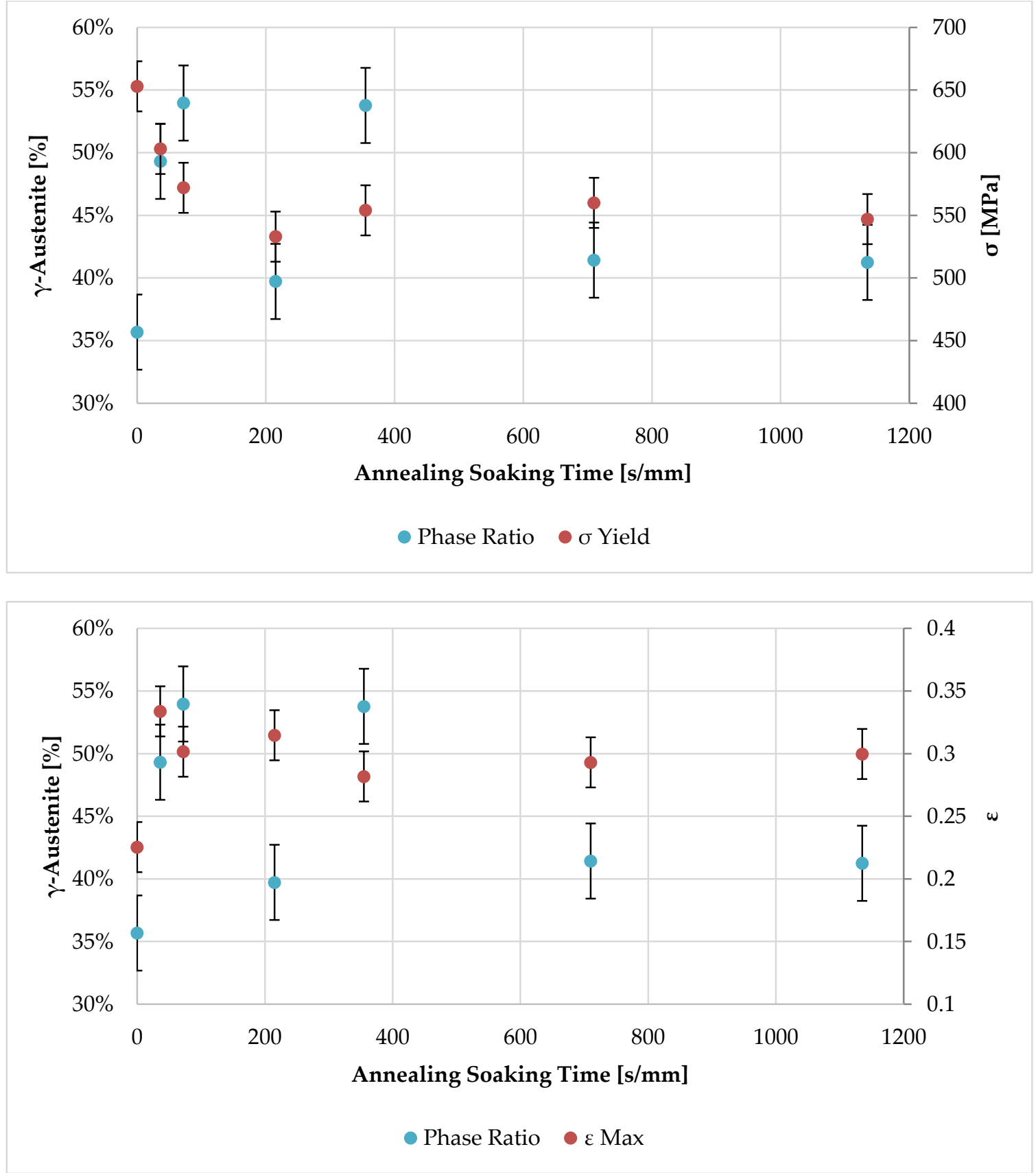

Figure 5. UNS S32760 tensile test results combined with the evolution of the phase ratio with the ongoing of the annealing thermal treatment. No specific trend appears; moreover, no correspondence can be underlined.

The phase fraction ratio of the un-deformed areas of the samples and of the highly deformed area next to the fracture surface has been evaluated via metallographical analysis, as reported in Figure 6 . 
A robust increase in the $\gamma$-austenite content has been measured in all the samples with a lower phase fraction ratio than the ideal equilibrium relationship of 50:50 ferrite:austenite microstructure. Moreover, in all the samples has been recorded a increment of the $\gamma$-austenite phase ratio associated to the diffusion-less growth martensitic shear precipitates. These increases match with a strain-assisted nucleation and growth phenomenon described by the Magee effect, testifying to the occurrence of a transformation induced plasticity event. Since martensitic phase transformation occurs without diffusion through a cooperative shear movement of atoms, it is recognized that the applied, as well as internal stresses, assist the transformation.

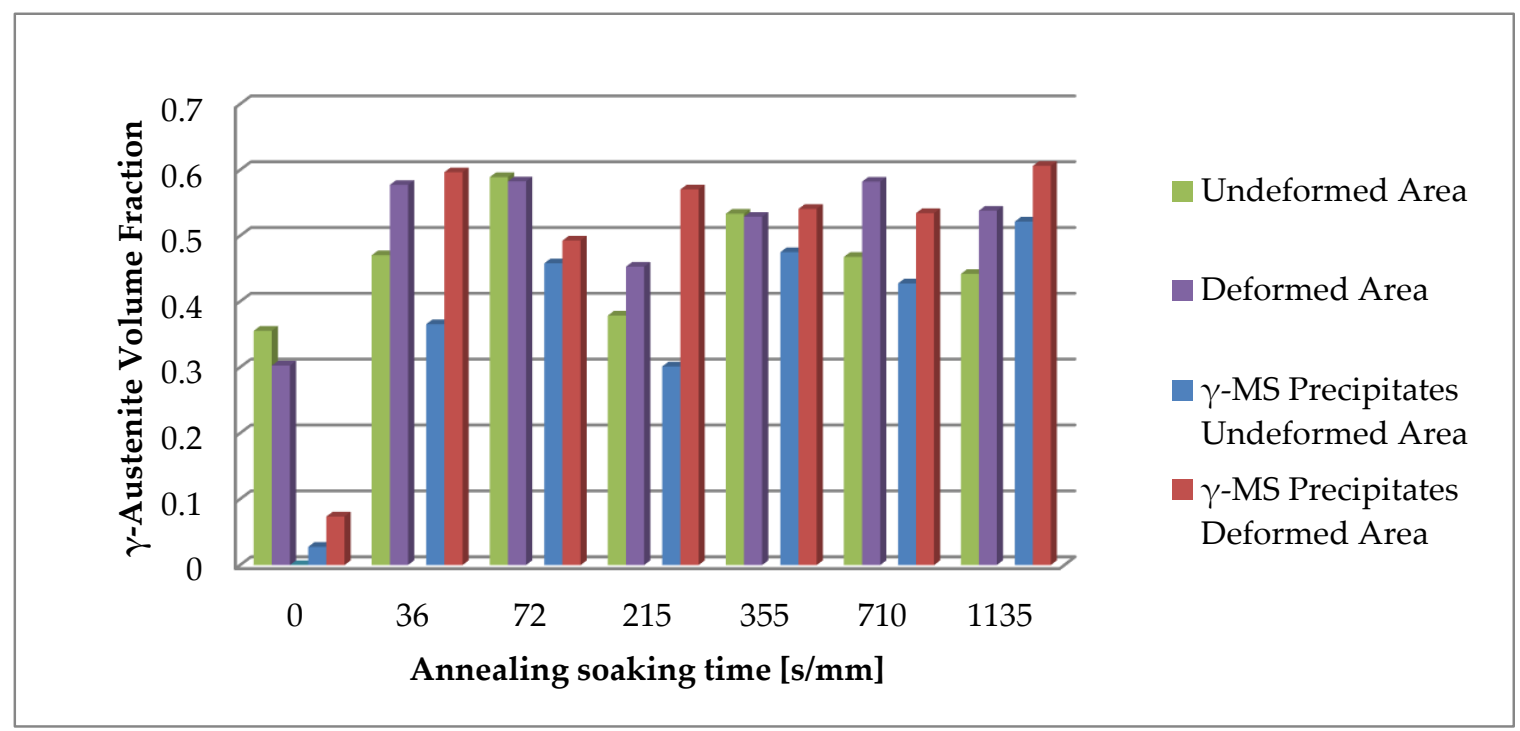

Figure 6. Comparison the $\gamma$-austenite phase ratio between the un-deformed and the deformed areas of the frature surface sections of the tensile samples. The increase in $\gamma$-austenite volume fraction between the two examinated ares, in particular regarding the Martensitic Shear precipitates, testifies to the occurrence of a strain-aided phase transformation phenomenon.

The presence of newly nucleated martensitic shear $\gamma$-nuclei, as can be stated by the much lower dimensions with respect to the other martensitic shear precipitates present nearby, along dislocations slip bands and the alignment of these particles to the dislocations structure testify to the occurrence of the Magee effect characteristic of TRIP effect phenomena, as reported in Figure 7.

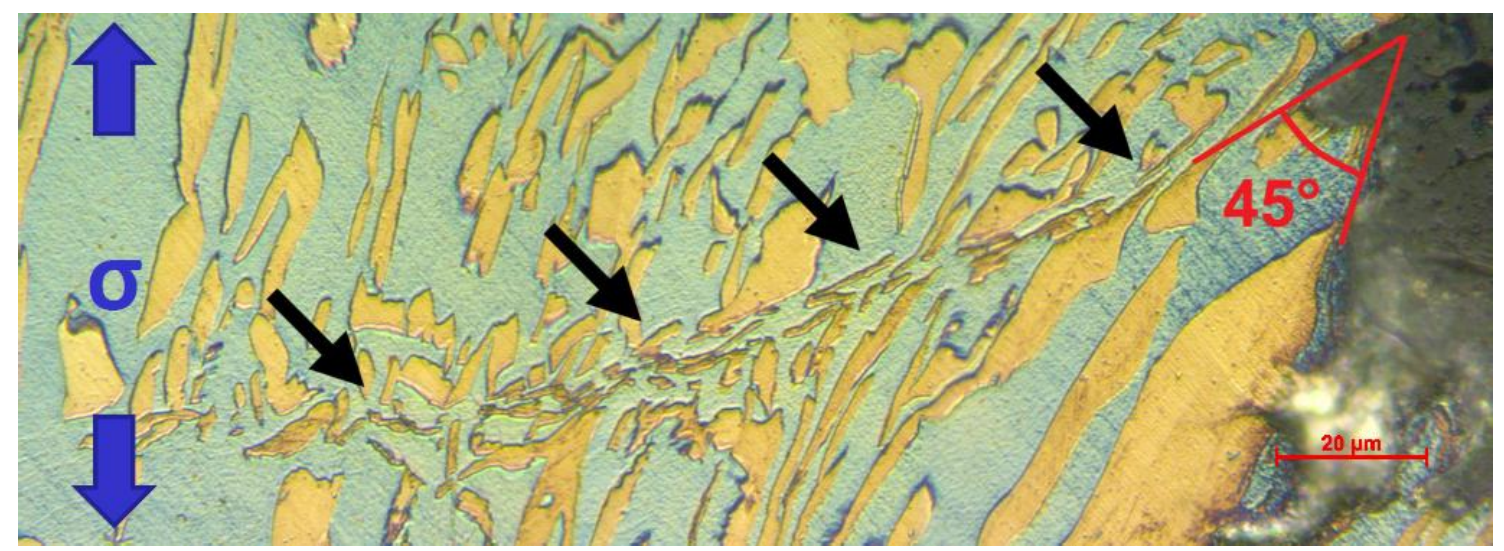

Figure 7. Newly nucleated martensitic shear $\gamma$-nuclei along dislocations slip bands and the alignment of these particles to the dislocations structure on the fracture surface section of specimen annealing treated for $355 \mathrm{~s} / \mathrm{mm}$ at $1353 \mathrm{~K}\left(1080{ }^{\circ} \mathrm{C}\right)$, due to the Magee effect. 
Since this phenomenon is related to the ability to nucleate martensitic shear $\gamma$-nuclei, it is consequently linked to the $\alpha$-matrix super-saturation in $\gamma$-former elements. Thus, the greatest ductility shown by the sample annealed for $36 \mathrm{~min} /$ inch at $1353 \mathrm{~K}\left(1080^{\circ} \mathrm{C}\right)$ has to be attributed to its ability to exploit the TRIP effect due to the highest $\alpha$-ferritic matrix supersaturation. Moreover, as could be expected by the relationship between the TRIP effect and the $\alpha$-matrix super-saturation, there are fewer occurrences of these processes in the samples corresponding to the maxima in the phase fraction ratio evolution during the annealing thermal treatment at $1353 \mathrm{~K}\left(1080^{\circ} \mathrm{C}\right)$ can be explained.

Further, the particular microstructural features, shown in Figure 7, evidences the strain-induced character of the occurring martensitic shear transformations, since the lattice defects generated by the strain act as nucleation and growth sites for the diffusion-less phase transformation. It can be confirmed also by the fact that the strain-induced martensitic transformation owns preferential shear directions, relative to the applied stress in just two variants accompanying the larger shear strain. Since this transformation results to be strain-induced, it can be remarked its occurrence at high strains regimes, where strain hardening reserves are usually more desirable $[37,38]$. Finally, the presence of newly nucleation of the martensitic shear $\gamma$-nuclei along dislocations slip bands can be definitively proven by the SEM/EBSD analysis (Figure 4). Since the frequency of occurrence of CSL boundaries $\Sigma 13$ for f.c.c. lattices is associated to the fast moving boundaries, testifying to the occurrence of nucleation and growth phenomena. Thus, the strong increase in CSL boundaries $\Sigma 13$ for f.c.c. $\gamma$-austenitic martensitic shear precipitates aligned to the dislocations structure shown in Figure 7, proves the occurrence of transformation induced plasticity phenomena [26,39].

\section{Conclusions}

The microstructure and deformation mechanisms of the commercial Super Duplex stainless steel F55-UNS S32760 were analyzed and discussed, after thermal heat treatments and tensile tests. The best combination of mechanical properties have been displayed after a solution thermal treatment at $1573 \mathrm{~K}$ $\left(1300^{\circ} \mathrm{C}\right)$ for $145 \mathrm{~s} / \mathrm{mm}$ and an annealing thermal treatment performed at $1353 \mathrm{~K}\left(1080^{\circ} \mathrm{C}\right)$ for $36 \mathrm{~s} / \mathrm{mm}$ holding time. These high results have been related to the occurrence of a transformation induced plasticity (TRIP) phenomena. This feature is generated by the Magee effect during the deformation. In detail, it results as a strain-induced martensitic shear transformation, triggered by the high density of lattice defects (as slip bands). Since this TRIP phenomenon results need to be strain-induced, it would occur at high strains regimes, where it is usually more desirable. Further, these effects are observed for the first time in commercial SDSSs, involve the martensitic shear precipitation transformation $\alpha \rightarrow \gamma$, and occur in a favorable phase ratio range for the corrosion resistance properties. All these aspects and easy thermal processing could grant the industrial exploitation of this phenomenon in the near future.

Author Contributions: A.F.C. conceived and designed the experiments, performed the experiments, analyzed the data and wrote the paper; S.B. conceived and designed the experiments and review the paper; C.D.C. performed the experiments and analyzed the data; A.D.S. contributed reagents/materials/analysis tools and review the paper; A.G. conceived and designed the experiments and review the paper; G.N. performed the experiments and analyzed the data; C.M. contributed reagents/materials/analysis tools and review the paper.

Funding: This research did not receive any specific grant from funding agencies in the public, commercial, or not-for-profit sectors.

Conflicts of Interest: The authors declare no conflict of interest.

\section{References}

1. Corradi, M.; Di Schino, A.; Borri, A.; Rufini, R. A review of the use of stainless steel for masonry repair and reinforcement. Constr. Build. Mater. 2018, 18, 335-346. [CrossRef]

2. Rufini, R.; Di Pietro, O.; Di Schino, A. Predictive simulation of plastic processing of welded stainless steel pipes. Metals 2018, 8, 519. [CrossRef] 
3. Di Schino, A.; Longobardo, M.; Porcu, G.; Turconi, G.L.; Scoppio, L. Metallurgical design and development of C125 grade for mild sour application. In Proceedings of the NACE-International CORROSION 2006, San Diego, CA, USA, 12-16 March 2006; NACE-06125. pp. 1-14.

4. Gunn, R.N. Duplex Stainless Steels, Microstructure, Properties and Applications; Woodhead Publishing: Cambridge, UK, 1994.

5. Alvarez-armas, I. Duplex Stainless Steels: Brief History and Some Recent Alloys. Recent Patents Mech. Eng. 2008, 1, 51-57. [CrossRef]

6. Nilsson, J.O. Super duplex stainless steels. Mater. Sci. Technol. 1992, 8, 685-700. [CrossRef]

7. Ciuffini, A.F.; Barella, S.; Di Cecca, C.; Gruttadauria, A.; Mapelli, C.; Mombelli, D. Isothermal Austenite-Ferrite Phase Transformations and Microstructural Evolution during Annealing in Super Duplex Stainless Steels. Metals 2017, 7, 368. [CrossRef]

8. Knyazeva, M.; Pohl, M. Duplex Steels: Part I: Genesis, Formation, Structure. Metallogr. Microstruct. Anal. 2013, 2, 113-121. [CrossRef]

9. Charles, J.; Chemelle, P.M. The history of duplex developments, nowadays DSS properties and duplex market future trends. In Proceedings of the 3rd Duplex World Conference, Beaune, France, 13-15 October 2010.

10. Southwick, P.D.; Honeycombe, R.W.K. Decomposition of ferrite to austenite in $26 \% \mathrm{Cr}-5 \% \mathrm{Ni}$ stainless steel. Metal Sci. 1980, 14, 253-261. [CrossRef]

11. Ohmori, Y.; Nakai, K.; Ohtsubo, H.; Isshiki, Y. Mechanism of Widmanstatten austenite formation in a d/y duplex phase stainless steel. ISIJ Int. 1995, 35, 969-975. [CrossRef]

12. Tomida, T.; Maehara, Y.; Ohmori, Y. Martensitic transformation from $\delta$-ferrite during the Melt-Quenching process of $\delta-\gamma$ duplex stainless steel. Mater. Trans. JIM 1989, 5, 326-336. [CrossRef]

13. Safdel, A.; Zarei-Hanzaki, A.; Shamsolhodaei, A.; Krooß, P.; Niendorf, T. Room temperature superelastic responses of NiTi alloy treated by two distinct thermomechanical processing schemes. Mater. Sci. Eng. A 2016, 684, 303-311. [CrossRef]

14. Sato, A.; Chishima, E.; Soma, K.; Mori, T. Shape memory effect in $\gamma \leftrightarrow \epsilon$ transformation in Fe-30Mn-1Si alloy single crystals. Acta Metal. 1982, 32, 1177-1183. [CrossRef]

15. Otsuka, K.; Ren, X.; Murakami, Y.; Kawano, K.; Ishii, T.; Ohba, T. Composition dependence of the rubber-like behavior in $\zeta 2^{\prime}$-martensite of AuCd alloys. Mater. Sci. Eng. A 1999, 273-275, 558-563. [CrossRef]

16. Dan, W.J.; Li, S.H.; Zhang, W.G.; Lin, Z.Q. The effect of strain-induced martensitic transformation on mechanical properties of TRIP steel. Mater. Des. 2008, 29, 604-612. [CrossRef]

17. Sohn, S.S.; Choi, K.; Kwak, J.H.; Kim, N.J.; Lee, S. Novel ferrite-austenite duplex lightweight steel with 77\% ductility by transformation induced plasticity and twinning induced plasticity mechanisms. Acta Mater. 2014, 78, 181-189. [CrossRef]

18. Patra, S.; Ghosh, A.; Kumar, V.; Chakrabarti, D.; Singhal, L.K. Deformation induced austenite formation in as-cast 2101 duplex stainless steel and its effect on hot-ductility. Mater. Sci. Eng. A 2016, 660, 61-70. [CrossRef]

19. Choi, J.Y.; Ji, J.H.; Hwang, S.W.; Park, K.T. TRIP aided deformation of a near-Ni-free, Mn-N bearing duplex stainless steel. Mater. Sci. Eng. A 2012, 535, 32-39. [CrossRef]

20. Knyazeva, M.; Pohl, M. Duplex Steels. Part II: Carbides and Nitrides. Metallogr. Microstruct. Anal. 2013, 2, 343-351. [CrossRef]

21. Pareige, C.; Novy, S.; Saillet, S.; Pareige, P. Study of phase transformation and mechanical properties evolution of duplex stainless steels after long term thermal ageing (>20 years). J. Nucl. Mater. 2011, 411, 90-96. [CrossRef]

22. Herrera, C.; Ponge, D.; Raabe, D. Design of a novel Mn-based 1 GPa duplex stainless TRIP steel with $60 \%$ ductility by a reduction of austenite stability. Acta Mater. 2011, 59, 4653-4664. [CrossRef]

23. Kocks, U.F.; Mecking, H. Physics and phenomenology of strain hardening: The FCC case. Prog. Mater. Sci. 2003, 48, 171-273. [CrossRef]

24. Caleyo, F.; Cruz, F.; Baudin, T.; Penelle, R. Texture and grain size dependence of grain boundary character distribution in recrystallized Fe-50\% Ni. Scr. Mater. 1999, 41, 847-853. [CrossRef]

25. Huang, J.C.; Hsiao, I.C.; Wang, T.D.; Lou, B.Y. EBSD study on grain boundary characteristics in fine-grained Al alloys. Scr. Mater. 2000, 43, 213-220. [CrossRef]

26. Beck, P.A. Annealing of cold worked metals. Adv. Phys. 1954, 3, 245-324. [CrossRef] 
27. Kobayashi, S.; Nakai, K.; Ohmori, Y. Isothermal decomposition of $\delta$-ferrite in a 25Cr-7Ni-0.14N stainless steel. Acta Mater. 2001, 49, 1891-1902. [CrossRef]

28. Zhang, J.; Huang, F.; Lin, Z. Progress of nanocrystalline growth kinetics based on oriented attachment. Nanoscale 2010, 2, 18-34. [CrossRef] [PubMed]

29. Balluffi, R.W.; Allen, S.; Carter, W.C. Kinetics of Materials; John Wiley \& Sons: Hoboken, NJ, USA, 2005.

30. Daróczi, L.; Palánki, Z.; Beke, D.L. Determination of the non-chemical free energy terms in martensitic transformations. Mater. Sci. Eng. A 2006, 438-440, 80-84.

31. Wan, J.; Ruan, H.; Shi, S. Excellent combination of strength and ductility in $15 \mathrm{Cr}-2 \mathrm{Ni}$ duplex stainless steel based on ultrafine-grained austenite phase. Mater. Sci. Eng. A 2017, 690, 96-103. [CrossRef]

32. Videau, J.-C.; Cailletaud, G.; Pineau, A. Experimental Study of the Transformation-Induced Plasticity in a Cr-Ni-Mo-Al-Ti Steel. J. Phys. IV 1996, 6, 465-474. [CrossRef]

33. Voronenko, B.I. Austenitic-ferritic stainless steels: A state-of-the-art review. Met. Sci. Heat Treat. 1998, 39, 428-437. [CrossRef]

34. Horvath, W.; Prantl, W.; Stroißnigg, H.; Werner, E. Micro hardness and microstructure of austenite and ferrite in nitrogen alloyed duplex steels between 20 and $500{ }^{\circ}$ C. Mater. Sci. En. A 1998, 256, 227-236. [CrossRef]

35. Fréchard, S.; Martin, F.; Clément, C.; Cousty, J. AFM and EBSD combined studies of plastic deformation in a duplex stainless steel. Mater. Sci. Eng. A 2006, 418, 312-319. [CrossRef]

36. Taleb, L.; Petit, S. New investigations on transformation induced plasticity and its interaction with classical plasticity. Int. J. Plast. 2006, 22, 110-130. [CrossRef]

37. Huang, B.X.; Wang, X.D.; Rong, Y.H. A method of discrimination between stress-assisted and strain-induced martensitic transformation using atomic force microscopy. Scr. Mater. 2007, 57, 501-504. [CrossRef]

38. Chatterjee, S.; Bhadeshia, H.K.D.H. Transformation induced plasticity assisted steels: Stress or strain affected martensitic transformation? Mater. Sci. Technol. 2007, 23, 1101-1104. [CrossRef]

39. Rutter, J.W.; Aust, K.T. Migration of «100〉 tilt grain boundaries in high purity lead Wanderung von

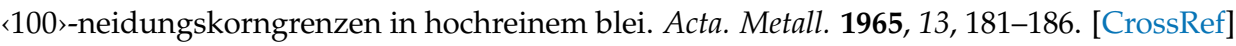

(C) 2019 by the authors. Licensee MDPI, Basel, Switzerland. This article is an open access article distributed under the terms and conditions of the Creative Commons Attribution (CC BY) license (http:/ / creativecommons.org/licenses/by/4.0/). 